\title{
Serious Games to Computer Networks Learning With CyberCIEGE: A Case Study in Brazilian Higher Education
}

\author{
Aliane L. Krassmann ${ }^{1}$, Andressa Falcade ${ }^{1}$, Luiz E. G. da Silva ${ }^{1}$, Roseclea D. \\ Medina $^{1}$ \\ ${ }^{1}$ Programa de Pós-Graduação em Ciência da Computação - Universidade Federal de \\ Santa Maria (UFSM) - Santa Maria - RS - Brazil \\ \{alkrassmann, andressafalcade, luizevandro.silva, \\ roseclea.medina\} @gmail.com
}

\begin{abstract}
Serious games are becoming emerging tools of educational support in the digital age. In this sense, the objective of this study is to evaluate the game about Computer Networks Security CyberCIEGE, in a higher education environment, to identify strengths and weaknesses in its use as a pedagogical tool. It was applied evaluations of the different game aspects. The research showed positive results that can assist in developing strategies for future serious games' use in the educational field.
\end{abstract}

Resumo. Jogos sérios estão se tornando ferramentas de apoio educativo emergentes na era digital. Nesse sentido, o objetivo deste estudo é avaliar o jogo sobre Segurança de Redes Computadores CyberCIEGE, em um ambiente de ensino superior, para identificar os pontos fortes e fracos na sua utilização como ferramenta pedagógica. Foram aplicadas avaliações dos diferentes aspectos do jogo. A pesquisa mostrou resultados positivos que podem ajudar no desenvolvimento de estratégias para o futuro uso de jogos sérios no campo educacional.

\section{Introduction}

The use of digital games for learning is becoming increasingly common - firstly, because the increasing society familiarity with this technology; secondly, due to the potential of games as educational tools, as it has high capacity to amuse and entertain people while encouraging learning through interactive and dynamic environments [Savi and Ulbricht 2008].

Serious games are used for purposes that do not only involve entertainment [Susi, Johannesson and Backlund 2007] but are characterized by the application of knowledge in an interactive way, with goals that challenge, amuse and motivate one, in order to transmit an ability or attitude applicable in real life [Almeida, Moita, Magalhães, Santos and Moreira 2011].

The difference between digital and serious games is the explicit and carefully thought-out educational purpose [Michael and Chen 2006], which makes the serious game a tool with specific features of video games, but with pedagogical objectives. According to [Cone, Irvine, Thompson and Nguyen 2006], tacit knowledge acquired through the application of concepts in a virtual environment can significantly improve student understanding. 
In this sense, this work aims to evaluate the application of a serious game, called CyberCIEGE, in a computer science undergraduate context, in order to analyze its performance as a technological tool of educational nature. The choice of CyberCIEGE occurred because the game is updated related with the authors' familiarity with the game environment.

The application of this study goes beyond the evaluation of the game itself, but to check for significant learning possibilities through serious games.

This paper is organized as it follows: section 2 brings a brief explanation of serious games and education; section 3 presents the CyberCIEGE game features; section 4 presents the methodology used in the study; section 5 shows the evaluation and analysis of the results and, finally, in section 6 the conclusion is displayed.

\section{Serious Games and Education}

Digital technologies evolve in order to improve and facilitate the teaching-learning process. The inclusion of serious games are on the rise in the educational field, by combining knowledge to entertainment, joint that has the potential to stimulate learning [Savi and Ulbricht 2008].

The purpose of these instructional approaches, according to [Greitzer 2007], are to replace or to complement the traditional lectures with active learning experiences, such as role-playing, simulations, own pace or team-based exercises, among other types of problems solving techniques that require critical and creative thinking.

Despite the advantages of using serious games in education, there are still several challenges to such use, aiming the expected positive results.

The authors [Savi and Ulbricht 2008] affirm that most educational games are still very simple, with limited diversity of activities compared to video games; tasks are poor and do not allow the progressive understanding of the subject.

When educational games are embedded in a classroom context, teachers will need to evaluate how well the students play the game and whether they've gotten enough of that experience [Klopfer, Osterweil and Salen 2009]. Serious games can be a great aid to engage students in a subject, but it can also cause distractions.

For all these reasons one should evaluate the game in order to identify the most appropriate usability and learning possibilities.

\section{The CyberCIEGE Game}

The CyberCIEGE game is a network security awareness tool that can support the training objectives of an organization, as it involves users in an adventure on the subject. It is an interactive game developed by the Postgraduate Naval School of the United States [Jones, Xiaohong, Carr and Huiming 2010] that can be applied to a wide range of audiences with different levels of technical sophistication [Cone, Irvine, Thompson and Nguyen 2006]. The player assumes the role of a security manager, taking management decisions to ensure that fictitious organizations are properly protected.

According to [Cone, Irvine, Thompson and Nguyen 2006], in CyberCIEGE players build, configure, operate and maintain their networks to allow virtual characters 
to promote the success of a venture. Each choice leads to a result in the game context, all while suffering constant attacks from hackers, vandals and virtual professionals.

This is a complex game which requires the player to learn a variety of new, and often difficult, skills and strategies to go through dozens of increasingly complicated levels. Often it requires the students both extracurricular research and collaboration with other players [Greitzer 2007].

The fundamental abstractions within the CyberCIEGE game engine are the assets, which are the information resources; users, usually employees of a company that have goals requiring computerized access to these assets; and attackers, who aim to usurp such assets. Some assets have substantial value for the company based on confidentiality or integrity. Others may have value depending on availability. Player's choices can affect the attacker opportunity (or thereof lack) of compromising the assets [Cone, Irvine, Thompson and Nguyen 2006].

\section{Methodology}

This qualitative exploratory study analyzed the possibilities of applying the CyberCIEGE game in an undergraduate environment for teaching Computer Networks. The audience was a group of 33 students in a sixth semester class of Computer Science course, in the Federal University of Santa Maria, Brazil. The total time of the study application was two and a half months, between September and November 2014.

The research took place in five steps, as the synthesis shown in Table 1 and discussed below.

Table 1. Steps followed on the methodological approach

\begin{tabular}{|c|c|c|}
\hline Step & Stage & Actions performed \\
\hline Step 1 & Pre-game & $\begin{array}{l}\text { Presentation of the methodology and the theoretical subsumers concepts about the } \\
\text { subject to the students. }\end{array}$ \\
\hline Step 2 & Pre-game & $\begin{array}{l}\text { Diagnostic survey on the prior students' knowledge, by applying a questionnaire about } \\
\text { the computer networks security topics previously presented and discussed on Step } 1 .\end{array}$ \\
\hline Step 3 & Game & $\begin{array}{c}\text { Presentation and practical time of CyberCIEGE game in the classroom, as well as } \\
\text { guidance to continue playing at home, in pairs. }\end{array}$ \\
\hline Step 4 & Post-game & $\begin{array}{c}\text { Diagnostic survey on students' acquired knowledge through the application of an } \\
\text { identical questionnaire to that of Step } 2 .\end{array}$ \\
\hline Step 5 & Post-game & $\begin{array}{l}\text { Application of a questionnaire about ergonomics and usability criteria in order to obtain } \\
\text { feedback from users about the game, and analysis of all the results. }\end{array}$ \\
\hline
\end{tabular}

In Step 1 (pre-game), the goals and the methodology adopted in the research were exposed to the class. Also the subsumers theoretical concepts about computer networks security were presented, from educational materials such as: the class handout provided by the discipline regent teacher; slideshow, audio-visual material, and examples from [ISH 2015]. For this activity, it was previously conducted a mapping of the issues (topics) addressed in the game scenarios, aiming to contemplate them on the subsumers contents presentation, among which may be mentioned: malicious code, attackers detection systems, security strategies, attacks, services protection, threats and security policies.

Step 2 (pre-game) focused on verifying the students' level of knowledge (expertise) before using the game. For this, it was applied a questionnaire consisting of 
20 objective questions about computer networks security, extracted from [QConcursos 2015] and according to the discipline contents, previously presented on Step 1.

In Step 3 the CyberCIEGE game was presented to the group of students in the class, in a mini tutorial format. Its main characteristics and features were demonstrated, so they could familiarize with the virtual environment. Students were instructed to download the game on their personal computers.

At this stage, to optimize the work, the class was divided into pairs, as some students had no personal computer or Microsoft Windows operating system (prerequisite for CyberCIEGE installation). The period established for practical game use was three weeks, contemplating the four weekly class periods and home activities. In addition to the classroom periods, students could ask questions through email or directly to the applicators, by pre-scheduling.

In Step 4, after the game playing period, it was applied the same questionnaire of the Step 2, aiming to conduct a new students' expertise survey, in order to identify if there were signs of learning improvement on post-game students. The students didn't receive the results of the first questionnaire, so they couldn't compare the answers.

When the Step 5 started, it was held a moment of informal conversation within the class, about the difficulties encountered and negative/positive points of the approach, in order to create a relaxed atmosphere that would allow a real, spontaneous and reliable feedback regarding the student's opinion. Then, it was applied the game evaluation questionnaire, comprising 46 questions, 11 objective and 35 essay, divided into four sections as described below.

The first section consisted of 6 diagnostic questions, aiming to indicate the student's familiarity with the English language (native language of the game) and digital games, drawing a possible analogy to its influence on the gameplay. The second section consisted of 12 questions around an ergonomic assessment of CyberCIEGE. The third section, composed of 13 questions, was responsible for the usability evaluation.

The fourth section consisted of 15 questions, proposing a pedagogical evaluation of the game and the approach adopted, in order to identify strengths and weaknesses in the application and in the research methodology, as well as elucidate overall students' criticisms and suggestions about the CyberCIEGE game.

The game evaluation questionnaire was elaborated by the authors. The issues of the sections two (ergonomic) and three (usability) were adapted from [Ergolist 2015], [Savi and Ulbricht 2008] and [Bober 2010].

From the methodology developed, two main instruments emphasize the analysis of the results:

a) The Knowledge Test: the test was performed before and after using the game. Some students were not present in first or second stage of the questionnaire application, thus they were not considered on establishing the final results. Therefore, for this analysis were taken into account 28 students.

b) The User's Feedback Questionnaire: about the game and the approach used at work, aiming to identify positive and negative game characteristics, in order to highlight future improvements for both CyberCIEGE as the implementations of others 
serious games case studies. It was not considered students who didn't participate on the first lesson or didn't play the game, resulting in 30 students.

In the following section an analysis of the results is performed, regarding especially ergonomic, usability and learning (pedagogic) criteria. It aims to identify possible improvements in this methodological approach, indicating advantages and disadvantages in composition and use of the game, pointing out directions for future adoptions of this or others serious games in educational field.

\section{Result Analysis}

To facilitate the analysis of the results, this section has been subdivided according to the focus of evaluation conducted, finalizing with improvements suggested by students.

\subsection{Ergonomic and usability evaluation}

The evaluation about the CyberCIEGE game itself and the approach taken began with a diagnostic survey. It was considered important to diagnose the English language knowledge and the level of participants' familiarity with digital and video games, analyzing the lack of both as a possible bad influence on gameplay.

It's showed that 22 students considered themselves among the intermediate and advanced levels of English language, although 3 said they didn't know it or it didn't influenced the gameplay of CyberCIEGE. Only 3 students pointed out not having much familiarity with video games, and 2 said that familiarity did not influence on using the game.

This diagnose can show that the native language of the game (English) and familiarity with games were not decisive factors for performance in the game, as the majority of the class had this knowledge/familiarity.

Main notes on the ergonomic evaluation elucidated by students are listed on the topics below.

a) About the displacement between the menu structures: 25 students answered they were able to perform the action of alternating between menus quickly and 26 said the menu panels were formed from a logical criterion of grouping options. This aspect was considered approved.

b) About the information to the game realization (gameplay): 20 students said it was available and 17 said they easily found the basic commands' list on CyberCIEGE. This aspect was considered approved.

c) Regarding error messages: 22 participants said it did not help solving problems and it did not provide the precise location and/or the specific or probable cause of the error, as well as the actions capable of fixing the problem. Nevertheless, 16 of them said that the button "help" were always present in these messages. This aspect was considered disapproved.

d) About the use of sounds and alert messages: 24 students said sounds were present and 20 said that in special situations requiring greater attention, the game showed warning messages in different places. This aspect was considered approved. 
e) Regarding the feedback: 19 students said it did not occur in all their actions, i.e., a lack of feedback in some actions. This aspect was considered disapproved.

After the ergonomic evaluation, the questionnaire treated about the game usability. Main notes from the students are listed below.

a) About facility to boot the game: 12 participants had little or no difficulty, but 15 had some difficulty and 2 had great difficulty in starting the game. Students said that updated hardware requirement was a negative point, as some students reported difficulty using the game at lower hardware settings. This aspect was considered disapproved.

b) Regarding the clarity of the language used in the dialogues: 19 participants said that it was partially or totally clear and 7 were indifferent to this aspect. The others participants said they encountered mixed or very complex messages. This aspect was considered approved.

c) About the ease of information: 15 students said the information was partially or totally easy to be understood, while 12 said the information was somewhat or very difficult to understand, with very broad objectives. This aspect was considered approved.

d) Regarding game functions: only 12 participants said the game functions were easy to learn and to remember, even with low familiarity, but the others were contrary to this statement. This aspect was considered disapproved.

e) About the number of game features: 21 students answered that this number is good for it to be possible to achieve the proposed objectives, but 8 have exposed that the game does not allow variations or alternatives to accomplish tasks. This aspect was considered approved.

f) Regarding the appearance of the game: 15 students said that it was not aesthetically pleasing, i.e., non-intuitive interface and difficult access, that for example the screen's resolution did not fit, so the student could not see some menus. Six participants were indifferent to this aspect. However, 17 students said the arrangement of objects were nice. This aspect was considered approved.

g) About the interactivity of the game: 15 students answered that the game allows good or excellent interaction, 10 were indifferent to this characteristic, remaining 5 participants that said the game allowed little or no interaction. This aspect was considered approved.

h) Regarding the influence of CyberCIEGE game familiarity on gameplay: 18 students said the job was not made easier from a greater familiarity with the game environment. This aspect was considered disapproved.

i) About the error situations: 20 students revealed that managed to reverse error situations from the most part of when it happened. This aspect was considered approved.

j) Regarding the students' opinion about the game use on computer networks discipline: 16 answered that it met the expectations partially or totally, while 
9 students were opposed to this statement. But 22 students felt an evolution in their learning with the gameplay. This aspect was considered approved.

The summary review on ergonomics' and usability's evaluations is shown in Table 2, which considered the majority opinion of participants (more than 50\% of the answers).

Table 2. Summary on ergonomics' and usability's evaluation

\begin{tabular}{|c|r|l|}
\hline Item & Description & Overall evaluation \\
\hline $\mathbf{1}$ & Displacement between menu structures: & Approved \\
\hline $\mathbf{2}$ & Information to gameplay: & Approved \\
\hline $\mathbf{3}$ & Error messages: & Disapproved \\
\hline $\mathbf{4}$ & Sounds and alert messages: & Approved \\
\hline $\mathbf{5}$ & Game feedback: & Disapproved \\
\hline $\mathbf{6}$ & Facility to boot the game: & Disapproved \\
\hline $\mathbf{7}$ & Clarity of dialogues: & Approved \\
\hline $\mathbf{8}$ & Ease of information: & Approved \\
\hline $\mathbf{9}$ & Game functions: & Disapproved \\
\hline $\mathbf{1 0}$ & Game features: & Approved \\
\hline $\mathbf{1 1}$ & Game appearance: & Approved \\
\hline $\mathbf{1 2}$ & Game interactivity: & Approved \\
\hline $\mathbf{1 3}$ & Game familiarity influence: & Disapproved \\
\hline $\mathbf{1 4}$ & Error situations: & Approved \\
\hline $\mathbf{1 5}$ & Game adoption on the discipline: & Approved \\
\hline
\end{tabular}

Analyzing the data in Table 2 it can be inferred that most of the game features were approved by students, resulting in a total of $67 \%$ approval, as shown in Figure 1.

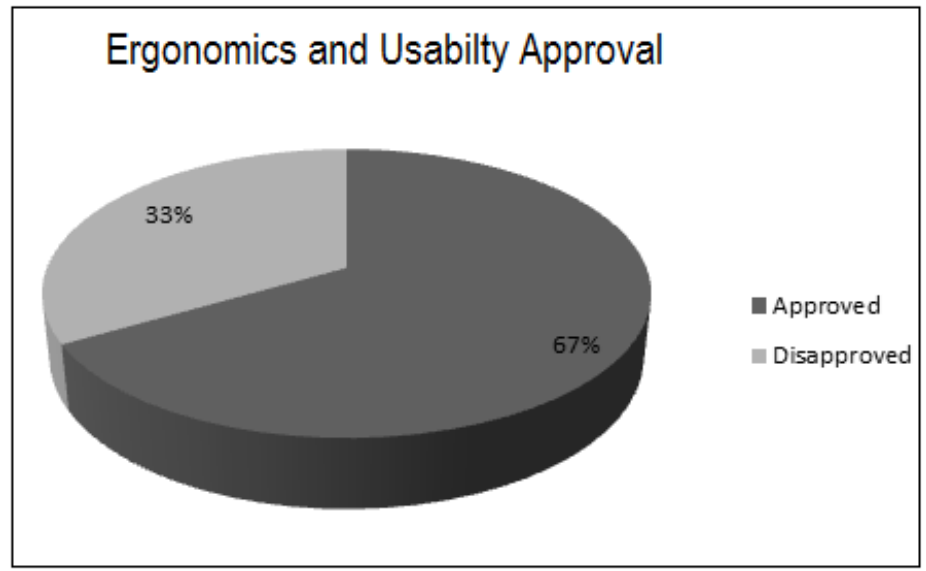

Figure 1. Percentage approval on ergonomics and usability criteria

\subsection{Pedagogical evaluation}

The knowledge test, consisting of 20 multiple-choice closed questions, treated with various issues related to computer networks security subject. The first application resulted in an average of 10.67 correct answers, a little above $50 \%$ of the total questions. 
Among the questions with the greatest number of right answers in the first step, were those dealing with network security concepts (integrity, interoperability, authenticity, confidentiality and availability), and information security in Virtual Private Networks (VPN). In contrast, among the questions that had more incorrect answers were those that addressed the types of attacks and security devices.

The second test application resulted in an average 10.86 correct answers, which represents a slight progress in learning. Ten students have improved the correct answers number regarding the first application, i.e., almost $30 \%$ of the class had a better result on post-game phase.

The pedagogical evaluation also surveyed positives and negatives aspects of the didactic approach, i.e., to be improved in the game application or in the discipline, as well as its use difficulties. In Table 3 the synthesis is displayed.

Table 3. Main positive and negative pedagogical aspects raised by students

\begin{tabular}{|c|c|}
\hline Main positive points & Main negative points \\
\hline a) Interactivity and dynamism shown by the game. & $\begin{array}{l}\text { a) Problems or errors in game operation, which hindered } \\
\text { the phases' progress and caused demotivation to } \\
\text { continue playing. }\end{array}$ \\
\hline \multirow[t]{2}{*}{$\begin{array}{l}\text { b) Wide range of real applicability possibilities in a } \\
\text { fictional environment, which provides a real } \\
\text { understanding of theoretical concepts, with means a } \\
\text { differential skill for those who plan to go to the labor } \\
\text { market. }\end{array}$} & $\begin{array}{l}\text { b) English language, making it difficult to play the game. } \\
\text { This note contrasts the diagnostic evaluation, where most } \\
\text { students said they were at an intermediate or advanced } \\
\text { level, and that this knowledge did not influence negatively } \\
\text { the gameplay. }\end{array}$ \\
\hline & $\begin{array}{l}\text { c) Missing aid to solving problems, which thereby caused } \\
\text { resolving it by trial and error, without necessarily knowing } \\
\text { what action resulted in the extinction of the problem. }\end{array}$ \\
\hline
\end{tabular}

Also in the pedagogical evaluation, a questionnaire raised students' suggestions on the game application methodological approach in computer networks discipline. Regarding this subject, some notes and demands of the students were:

a) Increased time to play the game, that is, stipulating weekly goals to be achieved, and that such gameplay occurred in the computers university lab.

b) More basic subsumers concepts before the game application and in the playing phases itself. Students felt lack of an explanatory introduction to each scenario and more tutorials that answered their questions about how to solve the presented problems.

Nevertheless, when asked about learning elapsed by playing CyberCIEGE, 24 students, representing $80 \%$ of the class, said the game helped learning contents of network security discipline, due its practical simulations, that translate realistic environments. On the motivation subject 16 participants, i.e., the class majority, said they felt more motivated to learn due to the use of the game.

\subsection{Game's improvements pointed out by students}

As suggestion for improvement in CyberCIEGE game, participants indicated the interface and help menus, which should be friendlier and homogeneous. Also, the objectives could be clearer, with more tips and information. A student pointed out that the game can be very complex for beginners. 
About changes to be made in CyberCIEGE, as a key point, students suggested the immediate correction of runtime errors, greater documentation of the game phases and scenarios, and the creation of a lighter version that requires less hardware for operation. Another widely cited aspect was the language of the game, i.e. the necessity of a version in Portuguese language (contrary to the assertion of the students in the diagnostic evaluation).

To conclude the overall evaluation it was left a space for comments and suggestions, where students could freely describe their thoughts about the game, its use and the pedagogical application. One of the students said that despite the faced problems, considered very valid the use of CyberCIEGE as it provides greater interaction with the concepts covered in class. Another student pointed out the importance of using practices like serious games for learning network security concepts. A student suggested a continuing use of the game. The main criticism that can be mentioned was the short period of the game use, the lack of real-time technical support and the few available tutorials.

\section{Conclusion}

The use of serious games in education must be accompanied by an assessment to identify the potential of the tool. Thus, the aim of this study was to evaluate the game CyberCIEGE in an educational environment of higher education, in order to ascertain the existing weaknesses and its performance as an educational object.

With the application of this case study and the student's feedback it was possible to prove the affirmation by [Savi and Ulbricht 2008], when they mention that restricted language and technical game installation requirements are negative characteristics that challenge teachers and students, as it was found this kind of difficulties on CyberCIEGE application.

Through the application of knowledge tests, responded twice to point out possible learning changes after applying the CyberCIEGE game (cognitive evolution), it can be seen that although small, there has been a change. Besides the knowledge acquired, student motivation was also improved.

Among the improvements on CyberCIEGE suggested by students is the interface, to make it friendlier, adjustments in the standard language (English) and fixing runtime errors encountered during practical activities.

Overall the students liked the application so it can be seen as a good pedagogical strategy. Some students reported the importance of user interaction with the content more dynamically allowed by games, and therefore the time of practical use of the game could have been extended.

As future work, it is intended to develop a proposal of instructional design for use of CyberCIEGE in the classroom, and the application of this approach in a longer period of time. Also, the improvement of the evaluation, with a control group, offering new possibilities for practical application of CyberCIEGE with pedagogical focus, which can be adapted to other serious games in education. 


\section{References}

Almeida, P.; Moita, L. P. M.; Magalhaes, R.; Santos, A.; Moreira, L.(2011). Serious games as an onboarding organizational tool for new employees. In. Information Systems and Technologies (CISTI), 2011 6th Iberian Conference on, IEEE.

Cone, B.; Irvine, C. E., Thompson, M. F., Nguyen, T. (2006). A video game for cyber security training and awareness. Computer Science Department for Studies and Research on Information Systems Security. Naval Postgraduate School, Monterey, CA, USA. Science Direct.

Ergolist. (2015). Checklist on ergonomic requirements for user interfaces. Checklist em requisitos ergonômico para interfaces com o usuário. Available in: $<$ http://goo.gl/iuYi2Y>. Acces in: januray, 15.

Greitzer, F. L. (2007). Cognitive science implications for enhancing training effectiveness in a serious gaming context. Pacific Northwest National Laboratory, Richland, WA. ACM Journal of Educational Resources in Computing, Vol. 7.

ISH. (2015). The Internet Security Hornbook. Cartilha de Segurança na Internet. Available in: $<$ http://cartilha.cert.br/redes/>. Access in: january, 15.

Jones, J.; Xiaohong, Y.; Carr, E.; Huiming, Y. (2010). A comparative study of CyberCIEGE game and department of defense information assurance awareness video. Computer Science Department. North Carolina A\&T State University, Greensboro, North Carolina, USA. IEEE.

Klopfer, E.; Osterweil, Scot; Salen, Katie. (2009). Moving learning games forward: Obstacles, opportunities and openness. The Education Arcade. Massachusetts Institute of Technology, USA.

Michael, D. R.; Chen, S. (2006). Serious games: games that educate, train and inform. Thomson Course Technology. p-287.

QConcursos. (2015) Concurrrent questions. Questões de concurso. QCX Educational Services. Available in: <https://qconcursos.com/>. Acces in: januray, 15.

Savi, R.; Ulbricht, V.R.. (2008) Educational digital games: benefits and challenges. Jogos digitais educacionais: benefícios e desafios. Revista Novas tecnologias na Educação. Renote. v. 6 n $^{\circ} 1$.

Susi T., Johannesson, M. and Backlund, P. (2007). Serious games: an overview. Web at Games Learning Society, GLS University of Wisconsin-Madison, Tech. Rep., Feb. 